\title{
OVER AND OVER: LOCAL FANS AND SPECTATOR SPORT TOURIST ENGAGEMENT
}

\begin{abstract}
This study investigates consumer engagement within the live sport-as-service industry by exploring the match-day experiences of spectator sport tourists. It highlights the importance of authentic and sincere experiences manifest through tourists' interactions with local fans. Data was collected via semi-structured interviews with international tourists who had visited Glasgow and attended a Celtic FC match. The findings demonstrate that football clubs may overlook the importance of consumer engagement, and that local fans are crucial in sustaining sports tourists' engagement. To this end, the findings suggest that tourist interactions with local fans can stimulate more memorable and enjoyable travel. Further, the vocal, visual displays provided by local fans contribute to an authentic and sincere travel experience. The study therefore suggests that local fans are a resource under-utilised by professional sports teams, with their contribution serving as a vital bridge between organisation and tourist in fostering engagement.
\end{abstract}

Keywords: spectator sports tourism; tourist engagement; sincerity; authenticity; football consumption 


\section{INTRODUCTION}

The consumption of live sporting events while travelling has emerged as a widespread and established leisure activity (Fourie \& Santana-Gallego, 2011). Here, tourists continue to look further afield for gratification stemming from unforgettable and rewarding travel embedded within the context of their beloved sporting pursuits. The consumption of professional football, while conventionally constrained by geography and demography (Jones, 2000), is no different, with around 800,000 overseas tourists attending live football matches in the UK annually (Magowan, 2015). This offers opportunities for firms operating within destinations hosting major sporting events (Daniels, 2007), but also more granularly for individual football clubs hoping to entice, engross, and sustain the interest of this lucrative cabal of customers, collectively spending around £680m per annum (Magowan, 2015). However, prior studies are often fixated with the economic dimensions of this influx (Daniels, 2007; Smith, 2005), with limited attention paid to tourist perceptions and behaviours, nor the potential that exists for service providers to engage with these visitors in a way that could convert them into steady revenue streams.

The importance of consumer-brand engagement - the means through which firms inspire consumers to engage with their offering in a dedicated, social, interactive, and participative fashion - is established (Pansari \& Kumar, 2017). Indeed, it has received sustained attention within the context of both tourism (Taheri, et al. 2014) and live spectator sport consumption (Yoshida et al., 2014). Regarding the former, high levels of engagement increase tourists' propensity to spend and increase the likelihood that they will recommend a destination or experience to others post-travel (Gannon et al., 2017; Thompson et al., 2018). The likelihood of tourists returning to a destination is a function of how memorable and enjoyable they find the experience (Bryce et al. 2015), which is itself positively influenced by engagement (Willson \& MacIntosh, 2008). Taheri et al. (2014) suggest that three distinct destination characteristics underpin engagement: 'attractors' to drive visitation; 'sustainers' to maintain interest; and 'relaters' to foster a personal relationship with the experience. All, in turn, combine to stimulate re-visitation. Looking specifically at consumer-brand engagement in professional spectator sports, Yoshida et al. (2014) suggest that positive engagement is cultivated and demonstrated in fans' 'non-transactional' behaviour, such as their willingness to reflect brand image via 'word-of-mouth' promotion to friends and family. 
Positive travel experiences are influenced not only by the perceived authenticity of the experience, but also by the perceived sincerity of tourists' interactions with local people (Kolar \& Zabkar, 2010; Taheri et al., 2018). Tourists develop more candid and consistent insights into destinations through interactions with locals (Zhou et al., 2015; Taheri et al., 2018), and tourists who pursue opportunities for socialisation do so to stimulate more memorable experiences (Kim, 2010). These dynamics are heightened within the realm of spectator sports tourism, where - in the context of football tourists, specifically - travellers prioritise and favour 'genuine' match-day experiences (Edensor, 2015), where the socialised and communal aspects of co-consumption stimulate personal commitment to the pursuit (Conner, 2014), and where the match experience itself resonates with symbolic value for those attending it (Gibson et al., 2003). Satisfactory engagement is therefore crucial to building memorable consumer experiences, and the football sector has embraced this. The emergence of progressively elaborate and interactive transfer announcements (Lang, 2017); novel experiences (e.g., Manchester City's Tunnel Club) (Hyde 2017); and organised events centred on narrowing the divide between players and fans (James \& Day, 2014), all serve to demonstrate how football clubs are adopting unusual approaches directed at encouraging fans to conceive that they are afforded unrestricted access to the intricacies of their favoured football clubs (Cordina, Gannon \& Croall, 2017). However, many of these engagement strategies focus primarily on locals, overlooking those who consume live sporting events while travelling.

As such, relatively little is known about the consumption practices and preferences of spectator sports tourists at present, and those who travel to consume football present a particularly interesting case study for these issues. While football sports tourists are likely to prioritise authentic match-day experiences, and although they are more likely to return to a destination if their experiences with locals are positive and welcoming (Chen \& Funk, 2010), football consumption is renowned for its partisanship and tribalism (Hewer et al., 2017). As such, from the perspective of the football 'industry', substantial opportunities and challenges surround the development and progression of this relationship, something which is itself deepened by the abundance of alternative consumer choices afforded to fans. Operationally, consumer engagement strategies may prove effective in transforming overseas visitors into consistent revenue streams, or indeed into dedicated, committed 'fans' themselves, by encouraging them to return (Yoshida et al., 2014) and by adopting the role of 'club 
ambassador' through recommending destinations and experiences to friends and family (Gannon et al., 2017).

Thus, important questions remain: how does the professional football industry best engage such consumers and benefit financially from their considerable spending power? To what extent do tourists pursue authentic consumption experiences, reflective of those of local fans? Moreover, what role do local fans play in developing this positive relationship and engagement between spectator sports tourists and football clubs? In response, this study turns toward a less internationally-ubiquitous context, nonetheless situated within the domain of spectator sport consumption: Celtic FC of Scotland. While not blessed with the international profile and overseas recognition of teams plying their trade in the English Premier League, Celtic FC matches are nonetheless known for a distinctive atmosphere supported by highquality service provision (Hewer et al., 2017) couched within a context (the Scottish football industry) that consistently attracts the highest per capita match-day attendances in Europe (McPartlin, 2018). As such, while Celtic FC possesses the necessary attributes to attract international tourists, it is likely to provide interesting insights into consumer engagement as it remains outside of the saturated environment typical of more widely-recognised alternatives within the UK sport-as-service industry.

\section{LITERATURE REVIEW}

\section{Spectator sport as a service}

Centred on its distinct entertainment value (i.e., the combination of live action, competitive endeavour and non-participation), there has been movement towards recognising the importance of spectator sport as a 'service' (Graham et al., 1995). Here, the industry has shifted. Far from serving as products taken in isolation, spectator sports are considered as a multitude of potential offerings (both commercial and non-commercial) underpinned by the opportunity for engagement, co-creation, and experiential consumption practices (Grove et al., 2012; Horbel et al., 2016). Consequently, the 'fan experience' - energised and influenced not only by the venue, staff, and the performance of the athletes (Grove et al., 2012), but also by fan engagement (both face-to-face and digital) with sports organisations pre-, during, and post-event - can be considered as the core of the spectator sports industry. Fans are drawn to personalised, memorable interactions which acknowledge the deep sense of identity, attachment, and loyalty they feel towards the organisation that they support (Jones, 2000). As such, it is important from an organisational perspective that commercial engagement too 
recognises this relationship as befittingly distinct, where fans - owing to their unique individual and collective, as well as historic and enduring, contribution towards shaping organisational culture - are regarded as more than mere customers, and where authentic experiences are identified, prioritised and cultivated (Hewer et al., 2017). Such actions are more likely to sustain engagement, where the immediacy and unpredictability of live spectator sports can do more for tourists in terms of highlighting the real culture of a destination than other heavily-curated alternatives (Cohen, 1988).

Recent figures highlight the commercial rewards available to organisations able to fully exploit the lucrative, largely stable, and commercially resilient live sports market (The Economist, 2009). For example, 74.5 million tickets were purchased for attendance at live sporting events in the UK in 2017 (Deloitte, 2017). While consumers were attracted in high volume to horseracing ( $\sim 6$ million), rugby union (5.5 million), rugby league (2.3 million), and the 2017 IAAF World Athletics Championships $(700,000)$, almost two-thirds of all tickets sold were for live football matches (47.6 million), which also included the UEFA Champions League Final, held in Cardiff. This reinforces the enduring position of football as both the sport of greatest national significance within Britain, and the extensive, international enticement that domestic - particularly top-level English Premier League - football continues to hold as an advantage over many of its competitors. However, because this drive towards increased commercialisation is manifest in the changing nature of the attending sports spectators themselves, a phenomenon particularly evident in association football (Kennedy \& Kennedy, 2012; Davis, 2015), there exists potentially disruptive challenges for sports organisations eager to satisfy consumers' desire for authentic experiences.

\section{Spectator sport tourism}

Sports tourism represents an integral component of serious leisure, which is itself characterised by the 'acquisition and expression of special skills and knowledge' (Stebbins, 1992, p.3). This is underpinned by a range of supplementary benefits derived in its pursuit, from improvements in health and wellbeing to career-focused re-skilling and socialisation (Curran et al., 2018), alongside a sense of dedication and productivity (Taheri, Jafari \& O'Gorman, 2014). Spectator sports tourism constitutes a sub-branch of this, differentiated by travellers' non-participation. However, as with other serious leisure pursuits, sports tourism is delineated by spectators' comparatively high levels of dedication and the ensuing sense of personal identity associated with sporting events or organisations (Jones, 2000). 
Correspondingly, extant research typically focuses on sports tourists' motivations for travel (Kurtzman \& Zauhar, 2005) and behavioural intentions (Kaplanidou \& Gibson, 2012), as well as the economic impacts that such travel induces (Smith, 2005). Still, others have attempted to ascertain the factors that influence memorable spectator sports tourism travel. Kruger \& Saayman (2012) suggest that high quality amenities and marketing serve as the most important contributory factors for spectators undertaking live marathon consumption. Beyond this, little extant literature examines facets of sustained consumer engagement at the nexus of spectator sports tourism and memorable travel.

Inbound spectator sports tourism is largely acknowledged to be economically beneficial to the host city, region, or country. However, small scale spectator sports tourism not linked to a larger (often international) event such as the FIFA World Cup or the Olympic Games - has the advantage of lower pre-requisite resource investments in host-city infrastructure (Allen et al., 2007). Despite the preponderance of association football clubs historically demarcating their supporter base along geographic or demographic boundaries (Jones, 2000; Conner, 2014), recent trends have seen an influx of sports tourists attending domestic UK football matches, with around 800,000 tourists visiting the country to consume live football annually, spending over $£ 650$ million in the process (Magowan, 2015). Tourists who attend live football matches also spend a greater amount on average ( $£ 855 /$ person) than those who did not attend a match (£682/person) (Foresight, 2015). Specific to this study, research indicates that small-scale sports tourism to Glasgow, primarily driven by attendance at matches featuring either or both of the city's “Old Firm” rivals Celtic FC and Rangers FC, is worth $£ 45.68$ million to the city’s GDP (Allan et al., 2007).

\section{Engagement: sports consumption and sports tourism}

'Engagement' is an established concept in consumption scholarship. It is primarily conceptualised as the way in which firms stimulate organisation-customer interactions and whether these interaction are conducted in a dedicated, collective, participative, and immersive manner (Taheri et al., 2014). In the context of professional sports consumption, Yoshida et al. (2014) identified three key engagement themes stimulating engagement. In particular, they identify consumer engagement in transactional behaviours (e.g., attending games; buying merchandise); non-transactional behaviours (e.g., word-of-mouth; participation) and a relational building aspect such as the maintenance of a long-term relationship with the team (e.g., through the purchase of season tickets). The authors develop 
a scale for non-transactional fan engagement behaviour, consisting of three elements (1) management cooperation - which includes involvement in activities which help team management, such as promotional events, (2) helping other fans through fan interaction and (3) performance tolerance - which considers the fans' relationship with the team during periods of poor performance. However, this scale does not consider specifically the engagement of sports tourists who do not normally reside in the city were the team is based.

Further, across tourism literature considerable attention has been paid to the concept of engagement (Taheri, et al. 2014). Highly engaged tourists are likely to spend longer at destinations; hold stronger positive opinions of their travel experiences; spend more on ancillary purchases (e.g., souvenirs, sustenance, supplementary experiences); and may be more likely to recommend or revisit destinations (Gannon et al., 2017). Nonetheless, some suggest that established classifications of consumer engagement remain inaccurate (Taheri et al., 2014). Here, three key factors are posited as stimulating consumer engagement, classified as: (i) attractors, (ii) sustainers, and (iii) relaters. 'Attractors' encourage individuals to undertake specific experiences while travelling, while 'sustainers' are important for ensuring that engagement persists through tourists' visits. Finally, 'relaters' are key to ensuring that consumers develop a connection with experiences, potentially resulting in a prolonged relationship between firm (and brand) and consumer (Cordina, Gannon \& Croall, 2017). As such, the memorability of travel can be improved by offering tourists a wider number and variety of engagement opportunities (Willson \& MacIntosh, 2008).

Some contend that those travelling to consume spectator sports believe it holds a degree of symbolic importance for tourists (Gibson et al., 2003). Further, 'a customer's role in the co-creation of value is unmistakable in spectator sport' (Grove et al., 2012, p.4). Thus, even in the context of live sport consumption, engagement is catalysed, hastened, and preserved in many ways (Taheri et al., 2014). For example, the overwhelmingly atmospheric, participative, and social reality of live sport consumption brings to mind many of the concerns necessary to catalyse engaged tourists (Edmond, 2006). The communal nature of spectator sport consumption help to foster commitment (often leading to engagement) and football matches could emerge as an acutely emphatic illustration of this (Conner, 2014). Such memorable experiences contribute to 'performance tolerance' - fans are likely to retain commitment and engagement towards their team irrespective of performance (Yoshida, et al 2014). The tourist-local interface offers visitors the opportunity to establish more dependable and frank insights to their travel (Zhou et al., 2015). In this regard, tourists eager to interact 
with locals often do so as they believe such interactions increase the memorability of travel (Kim, 2010). As such, interactions between tourists and local fans may prove crucial in creating value by providing the participative, co-created experience sought by many tourists (Pongsakornrungsilp \& Shroeder 2011; Rihova et al., 2015).

\section{Authentic spectator sport consumption and interactions with local fans}

The authenticity of the experience and any objects contained therein, and the perceived sincerity of tourists' interactions with locals, can contribute significantly to the overall travel experience (Kolar \& Zabkar, 2010; Taheri et al., 2018). The authenticity of travel destinations is typically considered through three distinct lenses: object-based (the provenance of a destination and the objects engaged with in-situ); existential (the emotional response engendered by the destination and objects found there); and constructive (destinations and objects designed and developed to appeal to visitors) (Curran et al., 2018). With regards to spectator sport consumption, tourists pursue provenance-heavy, real, and genuine match-day experiences (Edensor, 2015). Not to be confused with the notion of the 'authentic' football fan common to fandom literature (Davis, 2015), this conceptualisation of authenticity is experiential and destination-led - concerned with tourists' perceptions of their travel experience as opposed to their place within the wider fandom (Tanner \& Brown, 2001). As such, unlike the reimagined reality of constructed authenticity, this study places emphasis on its object-based and existential forms (Kolar \& Zabkar, 2010).

Object-based authenticity is primarily underpinned by 'how people see themselves in relation to objects' (Reisinger \& Steiner, 2006, p.74) they engage with, interact with, and experience at destinations. Resultantly, tourists' perceptions of authenticity are influenced by their desire to visit destinations of cultural importance and to interact and engage with genuine, place-appropriate objects there (Curran et al., 2018). As such, within the context of spectator sport tourism, emphasis may be placed on the legitimacy of merchandise available (Dixon, 2014), the tangential activities or entertainment (Edensor, 2015), or the grandeur of the stadium or service environment (Yalinay et al., 2018). Indeed, the emotions elicited by these object-based or interactive consumption elements can combine to influence tourists' perceptions of how authentic their travel experience has been (Kolar \& Zabkar, 2010).

Conversely, existential authenticity represents the object-free aspects of destinations and service environments, where the inter- and intra-personal feelings elicited by travel and cultural consumption influence tourists' perceptions of authenticity (Kim \& Jamal, 2007). 
Here, authenticity is derived from personal, historical, or cultural narratives where, in the context of spectator sport consumption, a connection to a particular sport, team, or athlete may generate the emotional connection required to ratify the authentic spirit of the destination (Hewer et al., 2017). Nonetheless, neither object-based nor existential authenticity exists in isolation, and extant research suggests that each form together contributes to tourists' overall perceptions of authenticity (Bryce et al., 2015; Kolar \& Zabkar, 2010).

However, one key aspect is often overlooked when investigating destination or service experience authenticity - the sincerity of the local people that tourists share their experience with (Taylor, 2001). While this is often characterised as the host-guest relationship (Sharpley 2014), spectator sport tourism serves as an outlier by embodying a long-standing form of collective consumption (Blackshaw, 2008). Nonetheless, sincere sports tourism may be driven by local fans actively interacting with inbound tourists to share the reality of their own cultural consumption experiences (Taheri et al., 2018). Here, 'the willingness of locals to interact with tourists in an accurate and meaningful fashion is important, as it allows them to share their experiences, culture and lives and quash suspicion regarding the "authenticity" of a destination' (Taheri et al., 2018, p.2). While engagement literature emphasises the importance of interactions with site employees, other tourists, and friends and family members while travelling (Taheri et al., 2014), little emphasis is placed on the importance of the perceived sincerity of tourists' interactions with local people in contributing to consumer engagement. The sincerity of local people in their interactions with tourists remains fluid and difficult to isolate (Wang et al., 2015), but it is important that the match day experience is not diluted for tourists' consumption, and instead tourists are provided with as authentic and sincere an experience as possible in order to best-represent the complex and highly context-specific nature of spectator sport consumption (Blackshaw, 2008).

Further, if tourist-local interactions are considered friendly, sports tourists may be more likely to return to a destination (Chen \& Funk, 2010). Due to their 'front-line' nature, it is nonetheless these interactions that may primarily stimulate co-creation between organisations and visiting tourists (Pongsakornrungsilp \& Shroeder 2011; Rihova et al., 2015). Nonetheless, football consumption remains underpinned by tribalism (Hewer et al., 2017), resulting in concerns around how to stimulate tourist engagement while offering them a glimpse of the candid reality of football fandom. Thus, with focus on consumer engagement, established strategies could prove crucial in shaping tourists' perceptions and 
experiences of spectator sport consumption (Yoshida et al., 2014). As such, given the lack of research into the behaviour and preferences of spectator sports tourists, coupled with the highly interactive, communal consumption space typical of live spectator sport arenas, the importance of perceived authenticity and sincerity in the domain of spectator sport tourism warrants further exploration.

\section{RESEARCH DESIGN}

This study focuses on Celtic FC, a professional football club located in Glasgow, Scotland. Current figures indicate that Celtic FC holds a worldwide supporter base of around nine million, and it has regularly been considered as one of the most recognisable brands within the global football industry (Brand Finance, 2015). Established in 1888 by Irish immigrants to support the city's impoverished (Giulianotti \& Robertson, 2006), community descendants still dominate the club's core support. Based on its friendliness, atmosphere and good behaviour, the fan-base received international recognition via the FIFA Fan Award in 2017 (FIFA, 2017). Nonetheless, Celtic remains a club rooted in 'counter-culture', conscious of its own identity and the values upon which it was founded, cognizant of the social, political and historic context from which it emerged (Kennedy \& Kennedy, 2013; McDougall, 2013). To this end, sections of the support have drawn unwanted attention to the club for their protestations and behaviour; receiving condemnation from, among others, club officials and directors (Hewer et al., 2017). However, in recent years the club has organised a number of non-competitive matches in overseas destinations home to significant numbers of Celtic fans, such as North America and Australia. These events draw significant crowds, contributing to widening the club's attraction beyond its more traditional support pools (Connor, 2014). However, while Celtic FC's history is littered with international recognition and triumphs, it is not presently considered an elite European football club and, notwithstanding participation in continental competitions, does not necessarily compete in a globally respected league.

To explore the antecedents, determinants, and manifestation of spectator sport tourist engagement, with emphasis on the role played by local fans, an exploratory qualitative research strategy was undertaken (Creswell \& Clark, 2011). A combination of purposive and snowball sampling were employed to identify individuals who visited Celtic Park while travelling to Scotland as tourists. Such techniques are widely used in tourism research as they provide access to interviewees who may otherwise prove difficult to identify. Whilst this 
brings with it a number of limitations, the purpose of the study is not generalizability. As such, this approach ensured that data was collected from tourists, and not local fans or the extant overseas supporter base. This was important for two reasons. First, the individuals studied are not locals, and are therefore unlikely to be familiar with the intricacies of attending a football match at Celtic Park and engagement opportunities therein. They are less inclined to feel any prior emotional attachment to this experience or this locale and thus engagement may be more difficult to stimulate. Second, they did not travel to Glasgow with the sole purpose of attending a football match. They arrived as regular tourists, eager to experience the City's offering. As such, their expectations may be less rigid than those who travel with specific intention of consuming spectator sports, and therefore the antecedents and determinants of their engagement may be less clouded by prior knowledge and preconceptions.

In-depth semi-structured interviews were conducted to encourage participants to use their own words and construct their own narratives when sharing their experiences of consuming live spectator sports while travelling (Creswell, 2013). Participants were briefed with regards to the purpose of the study, and encouraged to provide detailed explanations and insights, drawing upon examples and anecdotes where appropriate. Given the exploratory nature of this study, the interviews retained a conversational feel, but were nonetheless structured by an interview guide primarily comprised of key themes drawn from the literature (Table 1). With regards to the snowball sampling approach, each participant was asked to recommend other potential participants who might be interested in contributing to the study (Creswell, 2013). As a result, additional respondents were recruited during the data collection process. Following the exhaustion of available leads, interviews were conducted with a total of 22 international tourists, most of which $(63 \%)$ were from Europe (Table 2). Nonetheless, all were characterised by one point of commonality - they had visited the UK as tourists, and had attended a football match at Celtic Park, Glasgow in the period since August 2015. All interviews were conducted between January and June 2018, with each lasting around 45 minutes on average.

\section{[Table 1]}

[Table 2] 
Given the scope of this study and the inherent geographic spread of participants, the in-depth semi-structured interviews were primarily conducted via telephone and VOIP (i.e., Skype) services. If further clarifications were required, participants were approached inwriting and with additional responses provided in written format. Nonetheless, the majority of interviews were recorded and transcribed verbatim. At the request of the respondents, anonymity was guaranteed throughout, encouraging them to provide more accurate, honest, and reliable responses while protecting the privacy of the participants. The interviews focused on exploring the participants' spectator sport travel experiences, with an emphasis on Taheri et al.'s (2014) identified destination characteristics crucial to engagement; Yoshida et al.'s (2015) conceptualisation of fan engagement; the objects interacted with (e.g., at the match, on organised stadium tours, or when buying merchandise); the emotions elicited by their experience (Kolar \& Zabkar, 2010); and the nature and perceived importance of their interactions with locals (Taheri et al., 2018).

Regarding thematic analysis, the template approach was employed to investigate the participants' responses and themes emerging from existing literature (King \& Brooks, 2016). Given the existing literature on the topic, the template approach was considered to be the most effective for organising and analysing the data (Crabtree \& Miller, 1992). As mentioned prior, the interview guide provided a degree of structure to data collection, and this reflected the key themes drawn from the literature used in order to generate the initial analysis template (King \& Brooks, 2016). More specifically, as per King (2014), the main themes of the interviews represented higher-order codes: engagement, authentic live sport consumption, and sincere interaction. Further questions within the interview guide initially formed the basis of the lower-level codes (King, 2014). As such, the collected data was analysed using both a theory-driven and inductive approach (Miles \& Huberman, 2013).

This process remained exploratory in nature, and all codes were reviewed fluidly as understanding evolved and emergent outcomes were shared across the research team, contributing significantly to the consistency and validity of the study (King, 2014). Finally, all relevant data was categorised based on this combined inductive and theory-driven set of core categories in order to structure the subsequent discussion of the results in response to the underlying research questions. Whilst the core areas remained, related lower level questions were subsequently treated as one theme; for example the questions related to interactions with local fans, were categorised into two - those related to interactions prior to the match; and those related to the post-match experience. In order to ensure validity, the researchers 
initially generated categories independently, before sharing, discussing, and finalising them as a team (Burnard, 1991).

\section{FINDINGS AND DISCUSSION}

The findings reveal that the extant consumer engagement approaches prevalent across the football industry act to appropriately attract tourists (Taheri et al., 2014). Here, there is a degree of success with regards to inspiring tourists to consume live football matches while travelling. The majority of respondents had a degree of awareness with regards to Celtic's history and their recent domestic achievements. Others were encouraged by the dynamic and original marketing approaches employed by the club, especially on social media and the fan displays shown in European matches. For example, one participant indicated:

I wanted to see how it feels like to experience a game at Celtic Park, because from TV it seemed to be an amazing experience. The experience exceeded my expectations (Maltese participant)

Further, some participants endeavour to attend football matches in all cities that they travel to, and did not specifically visit Glasgow to watch Celtic. As one fan explained:

I do not plan my holidays/travelling around spectator sports. However, if I am in a city where a spectator sports event is happening, I look into attending if tickets are available. So it is not such an important part of my travel (Maltese participant)

In some cases, this desire to regularly consume live spectator sports when travelling extended beyond football consumption, with one participant indicating that:

I always try to do the best 'sport' thing when I travel, [specific to] the place I am visiting. I went to the Grand Prix in Monaco, Wimbledon Tennis in London, an NFL game in the USA... When I visited Glasgow it made sense to go there to see them [Celtic FC] play (Malaysian participant)

However, it may be difficult to sustain this initial engagement due to the inherent, often international, makeup of such overseas visitors. Fundamental information is necessary to contribute to the live sporting event and to increase the engagement of those consuming spectator sports while travelling. Some participants explained the functional difficulties associated with travelling to the stadium, such as issues surrounding public transport: 
It is quite a walk. But I feel that it takes less time than travelling by a crowded bus before or after the game (Dutch participant)

The stadium isn't in the city centre so it wasn't near our hotel. There seem to be trains running to it but we arrived at the station and they were quite full and unruly looking it is strange that the City's subway does not go to this major sporting arena - that would make things easier as in the end we got a taxi to the stadium to avoid hassle (Irish participant)

This is exacerbated by their conflicting wish to feel like part of the crowd, which is concurrently challenged by the desire to receive recognition for attending a football match in their capacity as 'tourist'. For some the experience was further curtailed by the cost of the merchandise: 'club stores of any football club sell over-priced merchandise (over £50 for a club shirt!), and I choose not to buy anything' (Maltese participant). For others, this emerged most pervasively while attending the football match, stemming from concerns with regards to the emphasis placed on an inferred or innate understanding of how to behave within and navigate the stadium:

The counter staff were friendly enough, but after I bought our tickets I felt like the process could have been explained a little better. In other arenas and museums and tourist attractions I have been given information packs and site maps, but I don't feel I was given enough information here. I felt like they had my money so I better just figure it out myself and get on with it (Irish participant)

This need for an experience is not uncommon, despite the notion that the consumption of live football is inherently experiential (Grove et al., 2012; Horbel et al., 2016). Here, some participants contend that the club has designed its service offering in a manner reflective of this. For example, one participant had also been on an organised tour of the stadium:

I got to go around the hidden parts of the stadium. My favourite part was getting to go into the trophy room and getting a photograph taken with some of the trophies the European Cup for instance - I had that picture as my Facebook picture for a long time' (Malaysian participant).

While prior knowledge can facilitate travel in the sports tourism context, even basic factors (e.g., seeing the stadium) (Conner, 2014) can influence sports tourists and maintain their interest while inspiring them to pursue supplementary service offerings, strengthening 
the firm-tourist relationship (Taheri et al., 2014; Yoshida, et al. 2014). In the case of our interviewees, the atmosphere within the stadium served as the main catalyst that sustained engagement throughout the match-day experience: 'The festive atmosphere and the supporters' continuous singing helped me engage more with the game' (Australian participant).

Here, there was emphasis on the benefits of social interaction and the clear and obvious role played by local fans in stimulating tourist interest and engagement. For example, one participant indicated that 'it was the craic with the fans that kept my interest the mostgreat banter and a real laugh for most of the game' (Irish participant). The participants recognised this and in doing so gained a better understanding of the factors peripheral to the sport itself that are of enduring importance to local fans. For example, one interviewee explained how a local fan explained the history of club and who the key players were to them: 'Local fans helped me understand who the famous players were on the posters on the side of stadium'. This, in turn, contributed to how authentic they perceived the experience to be as, without this unfiltered access to local fans they would be unlikely to come into contact with the 'symbolic currency through which intensive relativization occurs' (Giulianotti \& Robertson, 2006, p.175).

Spectator sport engagement goes beyond the 'transactional' aspect of attending football matches, and attending stadium tours (Yoshida et al., 2014). After the event, many of the participating sports tourists engaged in non-transactional fan engagement (Yoshida et al, 2014). For example, some explained how they used social media to share their experiences. Others indicated that this went beyond the event itself, and also wanted to share the atmosphere within Celtic themed pubs and the 'Celtic culture'. Here, additional social interaction with local supporters is likely to improve tourist engagement as it may increase the level of perceived authenticity experienced by sports tourists. As such, the intrinsically communal environment provided by professional football consumption may dilute consumer engagement lapses at a firm level by encouraging visitors to feel part of the established collective in such consumption environments:

'Local fans were welcoming ... they helped me to find my place to sit at the stadium and where to enter the stadium. They also explained some things to do with players to me when I asked. It was a lot of fun.' (Malaysian participant) 
As is evident from our interviews with the international visitors to Celtic Park, the 'authentic' element of their experience was essential. Bryce et al., (2015) highlighted the tension between modern advancements, and the retention of the authentic experience which the tourist expects. Whilst the commercialisation of football (Hewer et al., 2017) has brought with it inevitable changes to the Celtic experience (Donnelly et al., 2008), visitors at Celtic Park still want to feel part of the authentic experience. For example, one of the participants stated that: 'I bought some pie and Bovril for me...I'd heard it's the thing to do at Scottish football matches...' (Irish participant); and also 'bought a scarf from a seller outside the stadium for about $£ 6$ or something - seemed reasonable value to me and it made me feel like I fit in with all the other fans'. Here the findings suggest a new conceptualisation of 'objectrelated authenticity' (Kolar \& Zabkar, 2010) - where the tourist purchased the scarf (the object) to mimic the authentic experience that a local fan experiences while attending a match at Celtic Park and conform to local norms (cf. Derbaix and Decrop, 2011).

As part of the authentic experience, opportunities remain for the provision of curated local-tourist interactions. Such direction could improve the prospect of spectator sports tourists considering their interactions with local fans in a positive light. This interaction extended beyond the sports venue and continued in nearby pubs. Here, some tourists stated that they could better understand the importance of the sports team in the everyday life of the local football fans, resulting in a more authentic experience.

'The experience with local fans in the pub helped me to see the importance of the football team to the locals away from the stadium itself. All these guys talked about was the team, the players, the league position, and their rival teams. It seemed to consume them' (Australian participant)

Throughout the interviews, it became clear that authentic feelings were elicited by the tourists' visits to the sports venues and attending live sporting events. Here the authenticity is not related to objects (e.g., the sports stadium), but is perhaps more emotional - or rather an existential form of authenticity as referred to in the tourism literature (Kim \& Jamal, 2007; Kolar \& Zabkar, 2010; Reisinger \& Steiner, 2006).

'I was asking some questions to the boys sitting next to me and having a laugh with them and jumping about with them when the team scored, so I felt a sense of connection to them. Again, that's the beauty of watching sports live - meeting people 
you'd never usually meet and not feeling awkward about it because you are all there for the same reason really - to be entertained.' (Australian participant)

If positive, this socialisation may encourage them to return as burgeoning fans, or to act in a manner that promotes the club, the sporting 'product', and the tourist experience as a whole. Indeed, sports tourists pursue sincere experiences (Taheri, et al 2018); reflecting the real-life experience of local fans. As one respondent indicated, it is:

'Very important to see real lives of real football fans - it is not Disneyland - I like to see real lives of people when I travel and watching live sport is one way of seeing this. It is nicer than when I went to London I went to see Arsenal and I was placed with only other tourists - they just sit on phone taking video whole game - local fans do not do this they create atmosphere - it's fun!' (Malaysian participant)

For some tourists, this unique sincere experience is distinguished Celtic FC from football teams in their home country: 'local fans share stories of how their lives are and how they are related to the club. Celtic really is a family club. We don't have these types of football clubs in the Netherlands' (Dutch participant). Thus, interactions with local fans contribute towards providing the 'sincere' interactions that underpin memorable experiences. Such interaction goes beyond the terraces of the football stadium; tourists appeared eager to learn more directly about the club from the local fans, even whilst on organised stadium tour. For example, one respondent indicated:

'On the tour of stadium there were two guys - elderly - they were telling me about historic wins and success of the soccer team - seemed like the team was far better many years ago but it was nice to hear these stories from locals' (Malaysian participant)

This authentic, and sincere experience (Taheri et al., 2018) of engaging with a local football match is also one of the reasons why all respondents indicated they would recommend their experience with other fans (cf. Yoshida et al. 2014) - 'I recommend the Celtic experience, because I feel it is unique in Europe in terms of atmosphere and culture' (Dutch participant). Not only would they recommend their experience to others, but the memorable experience has led them to indicate that they would return in future if they visited Glasgow again (e.g., one participant indicated: "If I am in Scotland and there is a big match that interests me, then yes [I would revisit])", showing evidence of engagement with the 
event (Gannon et al., 2017, Yoshida, et al. 2014). The findings therefore highlight that the authentic and sincere experience of spectator sport tourists who visited Celtic Park was underpinned by the participative engagement stimulated by the perceived genuineness of their interactions with local fans. The findings therefore emphasise the importance of fans in co-creating value for both club and tourist (cf. Pongsakornrungsilp \& Shroeder 2011; Rihova et al., 2015). As one interviewee explained, the words attributed to the legendary Celtic manager Jock Stein remain relevant: 'football without fans is nothing' (Adams et al., 2017).

\section{RESEARCH IMPLICATIONS AND CONCLUSIONS}

Extant knowledge of the motivations, behaviours and evaluations of those consuming live spectator sports while travelling remains incomplete. Firms operating within the football industry must challenge the status quo. The difficult balance must be achieved between treating sports tourists in a manner representative of local fans, while recognising that they are likely to be unaccustomed to extant match-day customs. Attaining this may be crucial to sustaining consumer engagement - resulting in recurring visits or a propensity to recommend the experience to other international travellers. In general, extant consumer engagement approaches remain effective in enticing overseas visitors, many of whom recognise the potential enjoyment that can be derived from consuming live spectator sports. The findings reveal evidence of consumer engagement: through transactional behaviours (e.g., football match attendance; stadium tours); but also in non-transactional behaviours (e.g., photographs shared on social media). However, the findings indicate that this is influenced by whether they feel a sense of engagement with the communal aspects of the experience. Nonetheless, football clubs have a novel advantage in the domain of service delivery within the context of international tourism: (i) tourists consuming professional football are normally interested in the core entertainment provided - the 'match', and (ii) the international appeal of football may mean that tourists already have a degree of awareness of the football club whose product they are consuming, irrespective of geographic location.

In terms of theoretical implications, the findings emphasise the importance of sincere interactions with locals in shaping tourist experiences (Taheri et al., 2018). In doing so, this study contributes to the development of this nascent concept by demonstrating that sincere interactions are not constrained to the host-guest relationship (Sharpley 2014), and can instead have a wide-ranging effect on tourists' perceptions of service providers, event consumption, and destinations more generally (Taheri et al., 2018). Further, this study 
contributes to extant understanding of object-based authenticity (Kolar \& Zabkar, 2010). Here, a distinction is made between objects controlled and provided by the service provider (which subsequently improve the perceived authenticity of a destination) and objects interacted with and purchased with the purpose of engendering an affinity to the local people (in this case, merchandise purchased and worn provides tourists with a deeper sense of connection to the local fans). As such, the findings emphasise the important role authentic objects play in providing tourists with experiences analogous to those of locals, further stimulating perceived 'sincere' social interactions (Reisinger \& Steiner, 2006; Curran et al., 2018).

Beyond the local fan experience, there are further practical implications which arise from the findings. In order to sustain tourist engagement, football clubs must engender a hospitable, social match-day ambiance. Emphasis should be placed on providing tourists with detailed and freely available information, in terms of both match-day consumption opportunities and peripheral information pertaining to guided tours, souvenir shopping opportunities, and in-house hospitality provision to motivate overseas visitors to consider the match-day experience as greater than the sum of its parts (i.e., more than merely a sporting 'product'). In order to do so, training should be provided to a dedicated corpus of staff, primed to support spectator sport tourists. Further, emphasis must be placed on ensuring that signage is appropriate for tourists unfamiliar with the idiosyncrasies of the stadium.

Football clubs must also recognise the important role local fans play in shaping sports tourists' experiences. To attract visitors from abroad, they must to retain strong relationships with their fan-base and ensure that authentic and sincere experiences are maintained. Whilst recognising the global commercialisation of football, this study demonstrates that tourists visit sports venues not necessarily to consume a specific event, but also to feel part of an authentic and sincere experience. Therefore, marketing decision-makers should recognise that, the spectator sport experience can provide an authentic cultural portrait of a destination to tourists. The contribution of local fans in providing this should not be overlooked, and should instead be encouraged by adopting both a top-down (i.e., management-led) and bottom-up (i.e., local fan-led) approach to tourist engagement. Further, it may be difficult to promote such experience directly to tourists abroad. Football clubs should actively seek to organise more friendly matches abroad. Previous events organised by Celtic FC in North America and Australia drew significant crowds, and attracted international support (Connor, 
2014). If clubs encourage extant fans to attend such events, potential tourists may be encouraged to visit their home stadium when travelling in future.

This study provides a nascent understanding of spectator sport tourist engagement. However, some limitations must be acknowledged. While the data collection method and sampling strategy reflect the exploratory nature of the study, we recommend colleagues adopt a larger-scale quantitative approach to better-identify the determinants of engagement, and the extent to which sincere interactions with local fans contribute to sports tourist engagement. Moreover, future studies could focus on tourists consuming other spectator sports with typically partisan fandoms (e.g., rugby, European basketball, ice hockey) to explore whether the 'local fan' element of tourist engagement extends to other sporting contexts. Further, given the importance of sincere interactions with local fans, future studies should investigate the tourist-local interaction from the local fans' perspective. Here, there should be emphasis on exploring why local fans choose to interact with tourists when this is incongruent with the prevailing notion that insularity and tribalism characterises football fandom (Hewer et al., 2017). Further, as the practical implications emerging from this study recommend strengthening the link between organisation (e.g., the Football Club) and local fans by using them a key resource in improving tourist engagement, future studies should solicit data from decision-makers within such organisations in order to investigate the practicality of developing this approach. 


\section{REFERENCES}

Adams, A., Morrow, S., \& Thomson, I. (2017). Changing Boundaries and Evolving Organizational Forms in Football: Novelty and Variety Among Scottish Clubs. Journal of Sport Management, 31(2), 161-175

Allan, G., Dunlop, S., \& Swales, K. (2007). The economic impact of regular season sporting competitions: the Glasgow Old Firm football spectators as sports tourists. Journal of Sport Tourism, 12(2), 63-97

Blackshaw, T. (2008). Contemporary community theory and football. Soccer \& Society, 9(3), 325-345.

Brand Finance. (2015) Brand Finance and Football Brands 2012. Available at: http://www.brandfinance.com/images/upload/brandfinance football_brands_2015.pdf

Bryce, D., Curran, R., O'Gorman, K., \& Taheri, B. (2015). Visitors' engagement and authenticity: Japanese heritage consumption. Tourism Management, 46, 571-581.

Burnard, P. (1991). A method of analysing interview transcripts in qualitative research. Nurse Education Today, 11(6), 461-466.

Chen, N., \& Funk, D.C. (2010). Exploring destination image, experience and revisit intention: A comparison of sport and non-sport tourist perceptions. Journal of Sport \& Tourism, 15(3), 239-259.

Cohen, E. (1988). Authenticity and commoditization in tourism. Annals of Tourism Research, 15(3), 371-386.

Conner, N. (2014). Global cultural flows and the routes of identity: The imagined worlds of Celtic FC. Social \& Cultural Geography, 15(5), 525-546.

Cordina, R., Gannon, M. \& Croall, R. (2017). Over and over: consumer engagement and turning sports tourists into fans. In: Academy of Marketing: Tourism Marketing Special Interest Group (SIG), 2017-12-01, Heriot-Watt University.

Crabtree, B. \& Miller, W. (1992). A template approach to text analysis: developing and using codebooks. In B. Crabtree and W. Miller (eds.), Doing Qualitative Research, Newbury Park, CA: Sage

Creswell, J.W. (2013). Research design: Qualitative, quantitative, and mixed methods approaches. Sage Publications.

Curran, R., Baxter, I.W., Collinson, E., ... \& Yalinay, O. (2018). The traditional marketplace: serious leisure and recommending authentic travel. The Service Industries Journal, (in Press).

Daniels, M.J. (2007). Central place theory and sport tourism impacts. Annals of Tourism Research, 34(2), 332-347.

Davis, L. (2015). Football fandom and authenticity: a critical discussion of historical and contemporary perspectives. Soccer \& Society, 16(2-3), 422-436.

Deloitte. (2017, December 15). Almost 75m tickets sold for UK sports events in 2017 [Press Release] Retrieved from: https://www2.deloitte.com/uk/en/pages/pressreleases/articles/almost-75m-tickets-sold-for-uk-sports-events-in-2017.html

Derbaix, C., \& Decrop, A. (2011). Colours and scarves: an ethnographic account of football fans and their paraphernalia. Leisure Studies, 30(3), 271-291.

Donnelly, T., Donnelly, M., \& Donnelly, T. (2008). Take-over and turnaround at Celtic: the McCann years 1994-1999. International Journal of Sport Management and Marketing, 4(1), 49-61.

Edensor, T. (2015). Producing atmospheres at the match: Fan cultures, commercialisation and mood management in English football. Emotion, Space and Society, 15, 82-89. 
FIFA (2017) Activity Report 2017: The Year in Review. Retrieved from: https://img.fifa.com/image/upload/qxjpyt3niwbipbca0vmm.pdf [Accessed: $19^{\text {th }}$ June, 2018)

Foresight (2015, September) Football tourism scores for Britain: Inbound visitors that watch live football. Retrieved from https://www.visitbritain.org/inbound-football-tourismresearch

Fourie, J., \& Santana-Gallego, M. (2011). The impact of mega-sport events on tourist arrivals. Tourism Management, 32(6), 1364-1370.

Gannon, M.J., Baxter, I.W., Collinson, E., .. \& Maxwell-Stuart, R. (2017). Travelling for Umrah: destination attributes, destination image, and post-travel intentions. The Service Industries Journal, 37(7-8), 448-465.

Gibson, H.J., Willming, C., \& Holdnak, A. (2003). Small-scale event sport tourism: fans as tourists. Tourism Management, 24(2), 181-190.

Giulianotti, R., \& Robertson, R. (2006). Glocalization, globalization and migration: The case of Scottish football supporters in North America. International Sociology, 21(2), 171198.

Graham, S., Goldblatt, J.J., \& Delpy Neirotti, L. (1995). The ultimate guide to sport event management and marketing. Irwin Professional.

Grove, S.J., Pickett, G.M., Jones, S.A., \& Dorsch, M.J. (2012). Spectator rage as the dark side of engaging sport fans: Implications for services marketers. Journal of Service Research, 15(1), 3-20.

Hewer, P., Gannon, M., \& Cordina, R. (2017). Discordant fandom and global football brands:'Let the people sing'. Journal of Consumer Culture, 17(3), 600-619.

Horbel, C., Popp, B., Woratschek, H., \& Wilson, B. (2016). How context shapes value cocreation: spectator experience of sport events. The Service Industries Journal, 36(1112), 510-531.

Hyde, M. (2017). Manchester City's Tunnel Club player aquarium leaves the mind swimming | Marina Hyde. [online] The Guardian. Available at: https://www.theguardian.com/football/blog/2017/aug/23/manchester-city-tunnel-club [Accessed 26 Sep. 2017].

James, G., \& Day, D. (2015). FA Cup success, football infrastructure and the establishment of Manchester's footballing identity. Soccer \& Society, 16(2-3), 200-216.

Jones, I. (2000). A model of serious leisure identification: The case of football fandom. Leisure Studies, 19(4), 283-298.

Kaplanidou, K., \& Gibson, H. (2012). Differences between first time and repeat spectator tourists of a youth soccer event: Intentions and image approaches. Current Issues in Tourism, 15(5), 477-487.

Kennedy, P., \& Kennedy, D. (2012). Football supporters and the commercialisation of football: Comparative responses across Europe. Soccer \& Society, 13(3), 327-340.

Kennedy, D., \& Kennedy, P. (2013). Introduction: reflections on the context of 'Left Wing'fan cultures. Soccer \& Society, 14(2), 117-131.

Kim, J.H. (2010). Determining the factors affecting the memorable nature of travel experiences. Journal of Travel \& Tourism Marketing, 27(8), 780-796.

King, N. (2004). 'Using templates in the thematic analysis of text', in Cassell, C \& Symon, G (eds), Essential guide to qualitative methods in organizational research, SAGE Publications Ltd, London, pp.256-270

King, N., \& Brooks, J. M. (2016). Template analysis for business and management students. Sage.

Kruger, M., \& Saayman, M. (2012). Creating a memorable spectator experience at the Two Oceans Marathon. Journal of Sport \& Tourism, 17(1), 63-77. 
Kurtzman, J., \& Zauhar, J. (2005). Sports tourism consumer motivation. Journal of Sport Tourism, 10(1), 21-31.

Lang, J. (2017). How weird transfer unveilings became the Premier League's latest arms race. [online] The Independent. Available at:

http://www.independent.co.uk/sport/football/transfers/transfer-unveilings-becamepremier-leagues-arms-race-romelu-lukaku-naby-keita-a7828526.html [Accessed 26 Sep. 2017].

McDougall, W. (2013). Kicking from the left: the friendship of Celtic and FC St. Pauli supporters. Soccer \& Society, 14(2), 230-245.

McPartlin, P. (2018). Scottish football attendances 'highest in Europe' based on population. Retrieved from: https://www.scotsman.com/sport/football/competitions/premiership/scottish-footballattendances-highest-in-europe-based-on-population-1-4662193

Magowan, A. (2015). Overseas football fans visiting Britain now at 800,000. [online] BBC Sport. Available at: http://www.bbc.co.uk/sport/football/34197370 [Accessed 26 Sep. 2017].

Pansari, A., \& Kumar, V. (2017). Customer engagement: the construct, antecedents, and consequences. Journal of the Academy of Marketing Science, 45(3), 294-311.

Pongsakornrungsilp, S., \& Schroeder, J.E. (2011). Understanding value co-creation in a coconsuming brand community. Marketing Theory, 11(3), 303-324

Rihova, I., Buhalis, D., Moital, M., \& Gouthro, M.B. (2015). Conceptualising customer-tocustomer value co-creation in tourism. International Journal of Tourism Research, 17(4), 356-363.

Smith, A. (2005). Reimaging the city: the value of sport initiatives. Annals of Tourism Research, 32(1), 217-236.

Stebbins, R.A. (1992). Amateurs, professionals, and serious leisure. McGill-Queen's PressMQUP.

Taheri, B., Jafari, A., \& O'Gorman, K. (2014). Keeping your audience: Presenting a visitor engagement scale. Tourism Management, 42, 321-329.

Taheri, B., Gannon, M.J., Cordina, R. \& Lochrie, S. (2018). Measuring host sincerity: Scale development and validation. International Journal of Contemporary Hospitality Management. doi.org/10.1108/IJCHM-08-2017-0535

Tanner, J., \& Brown, A. (2001). Fanatics! Power, identity \& fandom in football. Canadian Journal of Sociology, 26(3), 517.

The Economist (2009, February 12) Sport: Is it recession proof? Retrieved from https://www.economist.com/node/13109631

Thompson, J., Baxter, I.W., Curran, R.,...\& Yalinay, O. (2018). Negotiation, bargaining, and discounts: generating WoM and local tourism development at the Tabriz bazaar, Iran. Current Issues in Tourism, 21(11), 1207-1214.

Wang, Y., Huang, S. and Kim, A.K. (2015). Toward a framework integrating authenticity and integrity in heritage tourism. Journal of Sustainable Tourism, 23(10), 468-1481.

Yalinay, O., Baxter, I.W., Collinson, E.,...\& Thompson, J. (2018). Servicescape and shopping value: the role of negotiation intention, social orientation, and recreational identity at the Istanbul Grand Bazaar, Turkey. Journal of Travel \& Tourism Marketing. Doi:10.1080/10548408.2018.1475277

Yoshida, M., Gordon, B., Nakazawa, M., \& Biscaia, R. (2014). Conceptualization and measurement of fan engagement: Empirical evidence from a professional sport context. Journal of Sport Management, 28(4), 399-417.

Zhou, Q., Zhang, J., Zhang, H., \& Ma, J. (2015), "A structural model of host authenticity", Annals of Tourism Research, 55, 28-45. 
Table 1. International participants' country of origin

\begin{tabular}{|l|r|}
\hline Country of Origin & $\begin{array}{l}\text { Number of } \\
\text { participants }\end{array}$ \\
\hline Australia & 3 \\
\hline Canada & 1 \\
\hline France & 1 \\
\hline Greece & 2 \\
\hline Ireland & 4 \\
\hline Italy & 2 \\
\hline Malaysia & 2 \\
\hline Malta & 3 \\
\hline Netherlands & 2 \\
\hline New Zealand & 1 \\
\hline Saudi Arabia & 1 \\
\hline
\end{tabular}


Table 2. Interview Guide

\begin{tabular}{|c|c|}
\hline Research Objective & Interview Questions/Prompts \\
\hline $\begin{array}{lr}\text { To explore } & \text { how } \\
\text { football clubs } & \text { engage } \\
\text { spectator } & \text { sport } \\
\text { tourists? }\end{array}$ & $\begin{array}{l}\text { Engagement } \\
\text { 1. Why did you choose to visit Celtic Park, or attend a Celtic match } \\
\text { when travelling? } \\
\text { 2. Do you typically attend spectator sport events when travelling? } \\
\text { Why? Is this important to you? } \\
\text { match-day experience? } \\
\text { 4. Did you undertake any supplementary experiences (tours, etc.) } \\
\text { during your visit? (Prompt: facilities during tours? Motivations } \\
\text { for going/not going on tours, etc.?) } \\
\text { 5. Were supplementary experiences appropriate for those with little } \\
\text { prior knowledge of the team (i.e., tourists)? } \\
\text { 7. Did you feel welcome/safe at the stadium? Why/why not? } \\
\text { (What was your experience buying a match ticket? (Prompt: } \\
\text { Assistance from local fans?) } \\
\text { 9. Waw clear was the signage around the stadium? } \\
\text { 10. Did you visit the Celtic Store at the stadium or in the city centre? } \\
\text { 11. What was your experience of this? } \\
\text { 12. Did you use social media to share your experiences? } \\
\text { 13. Will/did you recommend the experience to others? Why? } \\
\text { 14. Based on your experience, what aspects of your visit appeal most } \\
\text { to tourists? } \\
\text { 15. Did you provide feedback to the club following your visit? } \\
\text { (Prompt: Why? Process? Experience of this?) }\end{array}$ \\
\hline $\begin{array}{l}\text { To explore how } \\
\text { important 'authentic } \\
\text { consumption } \\
\text { experiences' are to } \\
\text { spectator } \\
\text { tourists? }\end{array}$ & $\begin{array}{l}\text { Authentic Live Sport Consumption } \\
\text { 1. Did your experience reflect the 'authentic' match-day experience } \\
\text { of supporters? In what sense? } \\
\text { 2. What objects did you interact with while attending the football } \\
\text { match? How did these objects contribute to how authentic you } \\
\text { perceived your experience to be? } \\
\text { 3hat merchandise did you buy? Why? Officially } \\
\text { licensed/branded? How did it contribute to the overall travel } \\
\text { experience?) } \\
\text { 4. What was your impression of the stadium and stadium concourse? } \\
\text { 5. Is the design of the stadium appropriate given its location in the } \\
\text { City that you visited? How does it compare to other sports arenas } \\
\text { that you have visited? } \\
\text { 6. How did your experience reflect the typical spectating experience } \\
\text { of local supporters? } \\
\text { Did you feel a connection to the related legends and history } \\
\text { 8. Durrounding the football club? } \\
\text { Do you think the experience was reasonably priced? Why? Do } \\
\text { 9. you think you paid more or less than local fans? } \\
\text { Did your visit provide you with a thorough insight into the }\end{array}$ \\
\hline
\end{tabular}




\begin{tabular}{|c|c|}
\hline & $\begin{array}{l}\text { football club? } \\
\text { 10. Do you consider your visit a unique experience? (Prompt: why?) } \\
\text { 11. What did you feel about the overall atmosphere during your visit? } \\
\text { What aspects did you enjoy most? } \\
\text { 12. Did you feel a connection to the local fans during your visit? How } \\
\text { was this manifest? }\end{array}$ \\
\hline $\begin{array}{l}\text { To explore how } \\
\text { important sports } \\
\text { tourists perceive } \\
\text { sincere interactions } \\
\text { with local fans to be. }\end{array}$ & $\begin{array}{l}\text { (Sincere) interactions with local fans } \\
\text { 1. What interactions did you have with local fans? } \\
\text { 2. How did your interactions with local fans influence your } \\
\text { understanding of Celtic FC? } \\
\text { 3. Were local fans eager to educate you with regards to the culture } \\
\text { surrounding the team (history, team, songs, chants, etc.?) } \\
\text { 4. Were the local fans comfortable 'being themselves' around you as } \\
\text { a tourist? How welcoming did you find local fans? } \\
\text { 5. Did you visit any pubs associated with local fans prior to/post- } \\
\text { match? If yes, describe your experience at these venues. } \\
\text { 6. Did the local fans provide you with a real sense of what it is like } \\
\text { to be a local fan? How? } \\
\text { Did you interact with local fans about issues related to the football } \\
\text { team? (Prompt: if yes, expand) } \\
\text { How important is it to you to see the real lives of real football } \\
\text { fans? } \\
\text { 9. How did the reality of your travel/spectator sport consumption } \\
\text { reflect your pre-travel expectations of the local fans? } \\
\text { 10. When you saw the local fans, how conscious were you of their } \\
\text { role within the place? } \\
\text { 11. How passionately do you feel that the local fans presented } \\
\text { themselves to you as a tourist? }\end{array}$ \\
\hline
\end{tabular}

